\title{
Not in their Minds
}

\author{
FRANCESCA VELLA
}

Mary Ann Smart, Waiting for Verdi: Opera and Political Opinion in Nineteenth-Century Italy, 1815-1848. California: University of California Press, 2018. 266 pp. ISBN 9780520276253 (hard cover).

IN the epilogue to Speaking into the Air: A History of the Idea of Communication, John Durham Peters sketches a picture of human interactions at once reassuring and ethically exacting. While a number of the once habitual media practices that he describes are swiftly becoming anachronistic (such as 'twist[ing] a radio dial or rustl[ing] a newspaper'), his overarching argument continues to hold significance. ${ }^{1}$ Peters's 1999 volume examines shifting understandings of communication at the intersection of social thought, philosophy, science, religion and psychoanalysis in the so-called West, particularly during the modern age. In the final chapter, he argues that the central problem with the process of communication, both face to face and over long distances, lies not so much in the interferences that media might cause to message delivery. Rather, the infinite gaps and malfunctions and short circuits in human interactions should be blamed on our inability to acknowledge our irreducible alterity. 'The problem of communication is not language's slipperiness, it is the unfixable difference between the self and the other,' as Peters puts it. ${ }^{2}$ In other words, successful exchange requires constant coordination, the subtle readjustment of one's strategy and position to the necessities of the other. One needs to give up fidelity to his or her 'truth' for co-creation of 'a dance in which we sometimes touch'. ${ }^{3}$ To approach communication from this angle is to downplay its modern, transmission-orientated understanding - the idea of media as 'message-bearing institutions' - and to return to an older understanding of the term: communication as what begets belonging, what enables community and communion. ${ }^{4}$

Email: fv250@cam.ac.uk

1 John Durham Peters, Speaking into the Air: A History of the Idea of Communication (Chicago, IL, and London: University of Chicago Press, 1999), 264.

2 Ibid, 266.

3 Ibid, 268.

4 John Durham Peters, The Marvelous Clouds: Toward a Philosophy of Elemental Media (Chicago, IL, and London: University of Chicago Press, 2015), 2. In his latest book, Peters eschews what he describes as a relatively recent, predominantly twentieth-century understanding of media as distributors of content and information, in favour of a more basic understanding of media as environments and infrastructures that sustain life. On the various meanings of 'communication', see Peters, Speaking into the Air, 6-10.

(C) The Author(s), 2020. Published by Cambridge University Press on behalf of The Royal Musical Association. This is an Open Access article, distributed under the terms of the Creative Commons Attribution licence (http://creativecommons.org/licenses/by/4.0/), which permits unrestricted re-use, distribution, and reproduction in any medium, provided the original work is properly cited. 
Here Peters gestures in a direction similar to that taken up by the media historian Kate Lacey in her recent exploration of listening in the media age. Lacey, who charts the evolution of the concept in relation to successive media technologies (particularly, but not only, of the twentieth century), takes issue with the dialogic framework, centred on voice and speech, that has dominated modern political and communication theory. Such a framework, she laments, has relegated listening to a passive, private act, to an empty political action with little bearing (unlike 'speaking up') on the ways in which we construct the public sphere. Instead, particularly as the era of broadcasting and rigidly compartmentalized production-versus-reception media ecologies is coming to an end, she suggests that listening deserves treatment as a form of attention and hospitality to others which has powerful agency. ${ }^{5}$

The ethical musings of media scholars grappling with the last hundred years of communication technologies might seem an unlikely point of departure for discussing a book concerned with Italian opera and the Risorgimento. Mary Ann Smart's Waiting for Verdi: Opera and Political Opinion in Nineteenth-Century Italy, 1815-1848 takes its cue from rather different and, for the most part, rather broken scholarly conversations: those that between the 1990s and the early 2010s weighed the place of nationalist politics in nineteenth-century Italian opera particularly Verdi's works and persona. These debates are summarized neatly in Smart's introductory chapter ('Risorgimento Fantasies', pp. 6-12); given further glosses in the final one, devoted to early 1840 s attitudes to Verdi, who later became Italy's most politicized composer ('Progress, Piety, and Plagiarism: Verdi's I Lombardi at La Scala', pp. 152-5); and settled in the Conclusion (pp. 179-83). It would be unnecessary - indelicate, even - for me to join here the multiplicity of voices already in conversation, not least since Smart goes to great lengths to move worn-out discussions forwards. For some time, after all, clouds hung over this corner of the scholarly world, divided as it was about matters such as compositional intention, how much we should read into documentary materials, and the extent to which we had let unconscious projection of present mindsets inflect what we said about theatrical experience in the past. This overcast is lucidly dispelled by Smart's poised writing - something for which we can be grateful. That from early on Smart draws attention to the place of reception materials in the entrenchment as well as confutation of powerful scholarly narratives is crucial not only for the revised conclusions that, by cautious handling of this and other types of evidence, she reaches on her subject, but also for larger methodological issues she thrashes out in her book.

Waiting for Verdi is one of a growing number of projects by opera scholars that, somewhat like Peters's and Lacey's in communication studies, are questioning some of the classic tenets of reception theory. Despite Smart's very different theoretical approach and her sensible refusal to dismiss reception history altogether, her project shares, I think, several of the premisses of Alessandra Campana's Opera and Modern Spectatorship in Late Nineteenth-Century Italy. ${ }^{6}$ Both books, to invoke Peters once more, foreground history as a problem of communication, the historian's hurdle as his or her wrestling with media of various stripes that most of the time stand out less for their neutrality or legibility than for their opacity and interfering. ${ }^{7}$ Campana's subtle close readings of the texts and paratexts that substantiated Italy's operatic fine secolo make

5 See Kate Lacey, Listening Publics: The Politics and Experience of Listening in the Media Age (Cambridge: Polity Press, 2013).

6 Alessandra Campana, Opera and Modern Spectatorship in Late Nineteenth-Century Italy (Cambridge: Cambridge University Press, 2015). For an insightful review of Campana's book, see that of Laura Protano-Biggs in Music and Letters, 98 (2017), 300-3.

7 See John Durham Peters, 'History as a Communication Problem', Explorations in Communication and History, ed. Barbie Zelizer (London and New York: Routledge, 2008), 19-34. 
for a book populated more by the operatic 'products' themselves than by the innumerable people crowding behind and around them; yet such readings ensue, much as in Smart's case, from a suspicion about the very categories reception theory requires that we assume. For apart from the limitations (far greater for the earlier than for the later part of the nineteenth century) that, as Smart observes, contemporaneous press materials - censored, linguistically cryptic and sparing in information - impose on us, to ask what opera meant to past audiences by sifting merely the critical responses this or that work and performance 'produced' means to uphold notions that are becoming increasingly untenable within the current atmosphere of cultural studies.

As Emanuele Senici has recently noted, 'reception [...] can risk implying a binary opposition' between the operatic work, standing “"come scoglio immoto” (still like a rock)' beyond history, and some kind of 'swirl[ing]', shifting surrounding. ${ }^{8}$ How ingrained the dualism has been in our disciplinary modes of enquiry for the last few decades is evident from the language Jim Samson confidently employed in 2001 to trace musicological interest in questions of reception. Writing for The New Grove Dictionary, he claimed that modernism's engendering of historical distance in or through art practice was attended in musicology by a new zeal to pursue the idea that in its afterlife a work threads its way through many different social and cultural formations. ${ }^{9}$ The telling apart of text from context - or medium from message, or sender from receiver - did much, as Smart and Nicholas Mathew elsewhere remind us, to unsettle the autonomy of the artwork and prod multiple forms of musicological engagement with the political, broadly understood. ${ }^{10}$ But scepticism is now looming within as well as outside the discipline, and the unease may soon lead us to plough new ground in our explorations of historical intercourses between aesthetics and ideology. ${ }^{11}$

Hence the significance of Smart placing the problem of communication right at the centre of her book. The theme of 'how opera communicates with and about the surrounding world' is the driving force behind all her rich musical and historical close readings (p. 8). In Waiting for Verdi, the term 'communication', either in this form or one of its derivatives (the adjective 'communicative' and the verb 'to communicate'), recurs more than 20 times, mostly in relation to how historical actors navigated the crucial in-between of theatrical and sociopolitical realities. Yet the way Smart strives to access the musical past - what so often nowadays goes under the name of operatic or musical 'experience' - is not by scouring solely, or even mainly, the prose accounts of contemporaneous receivers. It is not simply by inflating context at the expense of text (though the range and depth of historical knowledge that makes it into the book is impressive). ${ }^{12}$ Rather, a more diluted, more Latourian understanding of 'texts (and objects, and

8 Emanuele Senici, Music in the Present Tense: Rossini's Italian Operas in their Time (Chicago, IL, and London: University of Chicago Press, 2019), 10.

9 Jim Samson, 'Reception', Grove Music Online, <https://www.oxfordmusiconline.com> (accessed 24 August 2019) (emphasis added).

10 See Nicholas Mathew and Mary Ann Smart, 'Elephants in the Music Room: The Future of Quirk Historicism', Representations, 132 (autumn 2015), 61-78 (pp. 61-2).

11 For yet another take on the challenges faced by opera-reception scholars, particularly in today's increasingly digitized world, see the keynote lecture Roger Parker gave at the Second Transnational Opera Studies Conference in Berne in July 2017, 'Nineteenth-Century Operatic Reception History in the Age of Everything'. The lecture can be heard at <https://www.youtube.com/watch?v=wltAV wY4OA8> (accessed 24 August 2019).

12 See Rita Felski, 'Context Stinks!', New Literary History, 42 (2011), 573-91 (p. 582). Felski, whom Smart herself quotes in her book, observes that one of the key problems with context lies in 'the tacit beliefs about agency, causality, and control that steer acts of contextualisation' (p. 581). 
events) [... as] "gatherings" of human thought, effort, and action' sets the scene in Waiting for Verdi for hermeneutic operations that never let the aesthetic fall out of the picture (p. 15).

The reach of Smart's manoeuvres will be clearest if we peer into two particularly provocative chapters: 'Accidental Affinities: Gioachino Rossini and Salvatore Viganò' (Chapter 2) and 'Elizabeth I, Mary Stuart, and the Limits of Allegory' (Chapter 3). The former is an extensive meditation on the ways in which 'art in general began to matter differently to Italian audiences' at the height of Italy's Romantic debates, a meditation which Smart conducts on the trail of the exegetical activity (or lack thereof) set in motion around 1816 by an unsuspected double bill: Rossini's early Italian operas and Salvatore Viganò's pantomimic ballets (p. 24). The cultural context in which the two artists operated has traditionally been construed as a war between tradition and innovation, between the Classical values purported by Italian literature and new Romantic models that were starting to encroach from beyond the Alps. The choreographer's works, which often had mythological subjects and adapted pre-existing music (including much of Viennese origins), fitted this fraught aesthetic atmosphere like a glove, blending as they did the attractions of new 'disruptive' narrative strategies (such as the breaking of the Aristotelian unities) with balance and symmetry at the level of form.

But Smart's argument goes far beyond noting this lucky match. She suggests that what the ballets did for Italian audiences and the discourse of opera at the time was above all to encourage new Romantic forms of 'absorption and emotional engagement', forms that spectators soon learnt to export outside the theatre (p. 24). In the absence of evidence for how action and movements blended with music on stage, Smart builds her case drawing largely on contemporary criticism, an early Viganò biography and the few librettos and musical numbers surviving in piano-vocal collections. Desdemona's 'Canzone del salice' from Rossini's Otello (1816), the melody of which the choreographer revised and incorporated in his own eponymous work of 1818, is Smart's point d'appui towards showing how the proliferation of small-scale musical gestures articulating embodied emotion could become the hinge of a multimedia aesthetics - Viganò's - that grounded Rossini's elusive voices into more stable, more accessible semiotic terrain. Where the opera composer comes into Smart's story is indeed at the point when he can help throw the communicative power of Viganò's ballets into relief. Rossini's operatic compositions were famously dismissed as concessions to anti-mimetic impulses and sensualist pleasure; they fuelled contemporary moral anxieties through their author's lack of concern for dramatic truth and word-music correspondence, and they received little analytical attention. Viganò, on the other hand, was a deeply scrutinized and appreciated choreographer (almost Italy's 'absent Beethoven'); his 'mute, pantomimic bodies', more legible than untexted (or 'mistexted') music and less codified by tradition in their alliance with sound, had all the qualities that made them liberating (pp. 19, 32).

To draw attention to the subterranean work done by, say, isolated timbral effects or chromatic chains of sigh figures is certainly something quite different both from scanning musical compositions for supposedly 'encoded' political messages and from suspending all claims about their aesthetic language's capacity to impact on human bodies and emotions. It is, rather, to put one's finger precisely on the diminutive mechanisms through which art - crucially in performance and crucially at specific places and times - communicated. It is to attend to the musical past in ways remarkably historical, entrenched by the cumulative effects of intertextual pathways of signification and bygone practices of repeated listening. The decisive next step that Smart indeed takes in her exploration of early nineteenth-century Italian theatrical aesthetics is to gesture at the epistemological implications of a model of political theatre that - resisting our own, fundamentally Brechtian, mindset - posits immersive audience experience as the 
condition for its power to inflect so-called reality. Awareness of this kind of historical caesura has in one sense always underlain - albeit in tacit, inarticulate ways - narratives about opera and Risorgimento politics: the genre's supposed power to trigger patriotic action, to suck spectators up into a seamless amalgamation of reality and fiction. But I wonder whether the enticing move Smart implies here and yet leaves (I think) somewhat unresolved could not be taken further: whether we could not claim that some sort of disruption - from the comfortable zones of ensconced habits and expectations - is in fact latent in all political theatre; that the immersive 'shocks' felt by Viganò's spectators are tantamount to what it takes today to make us squirm in our seats and ponder critically what is happening on and beyond the stage.

Further reflections on opera's mediality lie at the heart of Chapter 3, which traces a fad for operas on Tudor settings that swept the Italian peninsula from 1815 to mid-century. The trend began with Rossini's Elisabetta, regina d'Inghilterra, premièred at Naples's San Carlo theatre straight after the end of the Napoleonic interregnum; it then continued with works by Donizetti, Mercadante and several others. At the centre of these works stands the female absolute monarch, usually caught in a jealous relationship with a rival queen. As Smart explains, these operas, and more broadly contemporary visual arts, moved gradually from the aesthetics of allegory - a device 'based in distance and indirection' and the subject of compelling reflections by Smart in the footsteps of the literary critic Barbara Johnson - to new mimetic strategies associated with Romantic subjectivity (p. 69). In order to reveal these works' historical and political significance, Smart adopts an approach close to Franco Moretti's 'distant reading', treating her Tudor operas chiefly as a 'collective entity' which she scans for recurring patterns (musical, dramatic and otherwise) (p. 90). This methodology has significant potential implications for how we conceive of reception history. In recent opera scholarship, this has often meant conducting archaeological operations aimed at 'excavating' discrete places and historical moments. As Smart observes:

The nine years and 130 miles that separate (for example) the premières of Mercadante's Maria Stuarda (Bologna, 1821) and Donizetti's Anna Bolena (La Scala, 1830) might momentarily shrink to near-invisibility, as will the half century and countless shifts of political power that elapsed between the historical events the two operas portray, in favour of attention to situations shared between the two (p. 62).

Far from losing sight of the idiosyncrasies of different cultural environments or falling into the traps of former comparative and cultural-transfer historiography, Smart embraces a methodology that enables her to reveal the politics of shifting representational modes.

The flexibility granted by this 'cluster' analytical approach appears most clearly from Smart's discussion of the second of two 'scenic archetypes' that she retraces in at least five Italian Tudor operas: the queen's signing of the death warrant for the traitor, a dramatic device that grew increasingly common in those works' final acts as tragic operatic endings became nearly imperative from the 1830 s onwards (p. 61). This scenic situation hinges on the materialization of the queen's abstract will in the form of a paper decree which (after many hesitations) she signs and of the ministers who ensure her decision is fulfilled. Smart's dwelling on this archetype means that the theme of communication is enfolded in this chapter at a double level. Smart directs our attention to the political implications of the 'deferral and mediation' enacted by the transmission of the queen's will onto the parchment and through her ministers (p. 95). How did these instances of mediated communication on stage speak differently to audiences in various corners of the 'real' Italian world? Are these scenes statements about (perhaps anticipations of ) modernizing governmental agendas, or are they reflections (if you like emanations) 
of shifting sociopolitical impulses? How do we want to connect this music with its cultural and political surroundings, say Bourbon Naples straight after the Restoration or Austrian Milan?

To put the problem in such black-and-white language is no doubt to be unfair to the subtle reasoning that informs Waiting for Verdi. Wisely, Smart does not side with either of the hypotheses above, simultaneously warding off the old ghost of discussion about composers' intentions and shedding the determinism that easily accrues around readings of cultural works that zero in on particular features to show them as "symptoms" of some underlying ideological framework' (p. 17). Yet asking those questions can still help us foreground the problem of music's agency - one of the chief bones of contention among (and beyond) scholars of opera and the Risorgimento. The closest Smart gets to addressing the matter explicitly is when, in Chapter 1, she explains that 'specific operatic scenes or musical passages can be heard as possessing social force', 'a social voice speaking through recurrence, pattern, and convention' (pp. 15-16). Chapter 4 ('Reading Mazzini's "Filosofia della musica" with Byron and Donizetti') deals with the problem of historical causality, revealing how a work such as Marino Faliero (1835) could gain 'a political force almost in spite of itself' within the Parisian community of Italian artists and political exiles via a combination of tightly knit intellectual collaborations, Venetian cultural resonances and musical-dramatic techniques of persuasion (p. 112). Smart's fascinating exploration of music in Parisian salons ('Parlor Games', Chapter 5) also contains engaging remarks about the ways in which, within - and only within - restricted circles of Italian expatriates, Italian songs could ignite a 'conversation among initiates', instilling in listeners the germs of an Italian sensibility through a series of 'veiled meanings' they could decode (pp. 143, 135). For the most part, however, Smart simply avoids mighty statements, and this as a corrective to the blunt, heroic narratives that for a long time entwined the paths of Italian politics and opera all too tightly and all too smoothly. What in Waiting for Verdi, at a musical level, contributes to historical motion are 'scattered sonic effects and small-scale modes of organizing dramatic time' (p. 183); discreet shifts in musical and dramatic procedures capable of 'accommodat[ing]' notions of social progress (p. 20).

In yet a broader disciplinary context, Smart's caution about questions of agency is analogous to the circumspection befitting sound and media studies scholarship concerning the problem of whether (and in what forms) music represents, embodies or articulates cultural and scientific ideas proper to specific places and times. At base, historians of music and technology and of musical nationalism face one and the same challenge: a challenge that emerges every time we attempt to capture in words, particularly in verbs, the transactions that constitute sonic objects in relation to other aspects of human culture. Smart points to 'morphologies' as a strategy long influential among scholars of opera and the Risorgimento to explain musical forms and dramatic devices in seamless continuity with political and emotional 'states of mind' (p. 7). Writings on sound and scientific developments are, for their part, vulnerable to precarious retreats into metaphorical vocabulary whenever they seek to eschew technological determinism. From this twofold perspective, musical examples are as easily wielded to confirm pre-existing claims about cultural and political 'context' as they are amenable to statements about other sorts of porosity between texts and their technological milieux. In Waiting for Verdi Smart avoids the pitfalls of both approaches. Her musical close readings home in on moments when music achieves efficacy. ${ }^{13}$ What she is interested in recovering is music's capacity to make an impact on history and societies, a capacity that is the result of a two-way process. Human

13 On music's 'efficacy' as opposed to (or alongside) music's 'about-ness', see Carolyn Abbate, 'Sound Object Lessons', Journal of the American Musicological Society, 69 (2016), 793-829. 
(or technological, or cultural) acts of musical 'creation' are in a sense no more consequential than the fragile, contingent conditions that make intersubjective communication through music now and again possible.

And that - to go back to my opening remarks sparked by Peters and Lacey - is perhaps the greatest achievement of Waiting for Verdi. Smart's book shows how the early nineteenth century knew little of the overt, conscious political uses of Italian opera as part of scripted patriotic demonstrations, programmes of satire or plot-based collusions between reality and theatrical experience - the 'stuff' that since unification has substantiated the myth of 'Verdi politico'. It also prods scholars in Italian studies to redress a certain disciplinary suspicion of, or at least resistance to, historical approaches that push beyond the question of how Italy and Italians have through the centuries been represented (and have represented themselves). ${ }^{14}$ But Waiting for Verdi above all helps us measure the distance that separates nineteenth-century forms of aesthetic and political participation from our own, illuminating the mechanisms that allowed Italian opera to function as a catalyst - in multiform, often analytically inconspicuous ways - for a national sense of belonging; and clarifying the contacts - of art forms, individuals and competing notions of progress - that nudged communication through. Smart recaptures a time when, far from channelling successfully or unsuccessfully ready-made political and cultural messages, opera did not give a thought to many of the potentialities we now regard as most essential to it. After all, if we sometimes fail to understand our ancestors, it may well be (as a famous author once put it) because we 'try to sort [them] on this or that side of a distinction which was not in their minds at all'. ${ }^{15}$

14 For a compelling study of historical representations of Italian national character and their role in nineteenth- and twentieth-century political discourse, see Silvana Patriarca, Italian Vices: Nation and Character from the Risorgimento to the Republic (Cambridge: Cambridge University Press, 2010).

15 C. S. Lewis, 'Is Theology Poetry?', The Weight of Glory and Other Addresses (London: William Collins, 2013), 116-40 (p. 132). 